\title{
Une dynastie de musiciens vietnamiens
}

\section{Tràn Quang Hai}

\section{OpenEdition}

\section{Journals}

Édition électronique

URL : http://journals.openedition.org/ethnomusicologie/2304

ISSN : 2235-7688

Éditeur

ADEM - Ateliers d'ethnomusicologie

Édition imprimée

Date de publication : 1 janvier 1988

Pagination : 140-143

ISBN : 2-8257-0159-9

ISSN : $1662-372 X$

Référence électronique

Tràn Quang Hai, « Une dynastie de musiciens vietnamiens », Cahiers d'ethnomusicologie [En ligne],

1 | 1988, mis en ligne le 15 août 2011, consulté le 19 avril 2019. URL : http://journals.openedition.org/ ethnomusicologie/2304 


\title{
UNE DYNASTIE \\ DE MUSICIENS VIETNAMIENS
}

\author{
Tràn Quang Hai
}

Au Vietnam, l'apprentissage de la musique se fait selon un mode de transmission courant dans la plupart des pays d'Asie. Normalement, l'élève vit de nombreuses années chez son maître et accepte de travailler comme domestique afin de pouvoir bénéficier de son enseignement, tout d'abord de façon indirecte, par l'écoute de sa pratique et de ses leçons, puis le cas échéant en étant reçu comme disciple. Mais les familles de musiciens traditionnels y sont rares. J'ai cependant eu la chance d'être né dans une telle famille, qui jouit d'une certaine réputation au Vietnam.

Né en 1830 à Huê, ancienne capitale du Vietnam, mon arrière-arrièregrand-père paternel s'appelait Tràn Quang Tho. Musicien à la cour de Huê, il était un remarquable joueur de luth piriforme dàn ty bà. Mais en 1863, à la suite de la défaite de l'armée vietnamienne contre la puissance française, le sud du pays devint une colonie de la France connue sous le nom de Cochinchine. Cet événement décida mon aïeul à quitter la capitale impériale et à s'établir dans un village du sud. Il y menait une vie austère, consacrant ses loisirs à la pratique de la musique.

De ses sept enfants, seul le cinquième, mon arrière-grand-père Tràn Quang Diem (1853-1925) se consacra à la musique. Il devint expert dans le style de Huê autant que dans la musique du sud et notamment celle de la province de Quang Nam, propagée par deux musiciens : Nguyen Lien Phong et Nguyen Tong Ba. Il jouait de deux instruments : le dàn ty bà et le luth en forme de lune à deux cordes appelé dàn kìm ou dàn nguyêt. Il rénova aussi le système d'écriture musicale en y introduisant la notation en rouge pour les temps forts, ce qui permettait de faire apparaître la notion de durée dans la transcription schématique.

Tràn Quang Diem est l'auteur de plusieurs compositions pour luth piriforme, qu'il avait notées avec d'autres pièces de son répertoire dans un cahier qui a malheureusement été perdu. Il passe aussi pour avoir créé les huit pièces royales bài ngu à l'occasion de la venue de l'Empereur Thành Thai dans le sud. Ce serait son parent Diep Van Cuong, époux d'une princesse royale, qui lui aurait suggéré cette composition. Toutefois, mon ancêtre n'a jamais joué cette pièce en public, laissant à un autre musicien nommé Ba Doi le soin de le faire. C'est pourquoi certains interprètes, tel Nam Hung, en attribuent à tort la paternité à $\mathrm{Ba}$ Doi. La controverse subsiste encore actuellement. 
Mon arrière-grand-père enseigna la musique à deux de ses enfants : la deuxième, sa fille Tràn Ngoc Vien, qui apprit à jouer du dàn ty bà, et le cinquième, mon grand-père Tràn Quang Triêu, qui devint spécialiste du dàn kìm. Un de ses autres élèves était le père du maître de cithare Nguyên Vinh Bao.

Ancien élève du lycée français de Saïgon, Tràn Quang Triêu (1897-1931) passait pour quelqu'un d'ouvert à l'influence de l'Occident. On raconte que, passionné par l'hypnose et le magnétisme, il s'amusait à faire dormir les surveillants du lycée afin de pouvoir s'adonner à la musique sans être dérangé. Ayant l'esprit inventif, il créa un nouvel accordage, en septième mineure, des deux cordes du dàn kìm. Utilisé surtout pour les pièces tristes, cet accord est connu sous le nom d'" accord de la pure orchidée (dây tô lan) de Monsieur Bay Triêu ".

Maîtresse de musique et d'arts ménagers au collège de jeunes filles Truong Ao Tim de Saïgon, sa sœur Tràn Ngoc Vien (1885-1944) était également joueuse de cithare à seize cordes dàn tranh, qu'elle apprit du maître Chin $\mathrm{Ky}$, et directrice d'une troupe de théâtre féminine appelée Ganh Dong $N u$. Cette initiative visait à changer l'opinion publique sur les actrices, qui avaient habituellement mauvaise réputation. Observant une discipline assez stricte, ses élèves partageaient leur temps entre les études générales, l'apprentissage du théâtre et les arts martiaux. Mon grand-oncle Nguyen Tri Khuong, frère de ma grand-mère paternelle, composa une partie de leur répertoire. D'autres membres de la famille étaient aussi musiciens : un de ses frères était percussionniste, spécialisé dans le jeu des tambours rituels, un autre flûtiste et compositeur, et un troisième joueur de luc huyên câm, un type de guitare espagnole transformée et adaptée à la musique vietnamienne.

L'union de ces deux familles de musiciens a donc enrichi notre tradition musicale. Cette génération a aussi œuvré pour un rapprochement avec la musique occidentale par l'utilisation d'instruments comme le violon et la guitare pour la musique traditionnelle et par l'adaptation de textes vietnamiens sur des mélodies françaises comme la Madelon ou la Marseillaise.

Mes grands-parents eurent trois enfants: mon père Tràn Van Khê, né en 1921, mon oncle Tràn Van Trach, né en 1924, et ma tante Tràn Ngoc Suong, née en 1926. Cette dernière était une chanteuse de variétés assez connue dans les années cinquante. Tràn Van Trach était un bon joueur de luth piriforme, mais il s'intéressait peu à la musique traditionnelle; il se fit surtout connaître comme fantaisiste et auteur de chansons comiques. Mon père est, de ce fait, le seul à avoir perpétué la tradition musicale familiale, tout en offrant une contribution de premier plan à la diffusion de la musique vietnamienne dans le monde.

Entouré de musiciens de toutes parts, mon père a baigné dans une ambiance musicale dès son plus jeune âge. Il a ainsi appris à jouer de nombreux instruments : du luth dàn kìm avec son père, de la cithare dàn tranh avec sa tante - bénéficiant de ce fait indirectement de l'enseignement du maître Chin $\mathrm{Ky}-$, du tambour et de la guitare luc huyên câm avec ses oncles. Il étudia, en outre, la théorie musicale traditionnelle dans le cadre familial, parallèlement au solfège et à l'harmonie au lycée de Saïgon. 


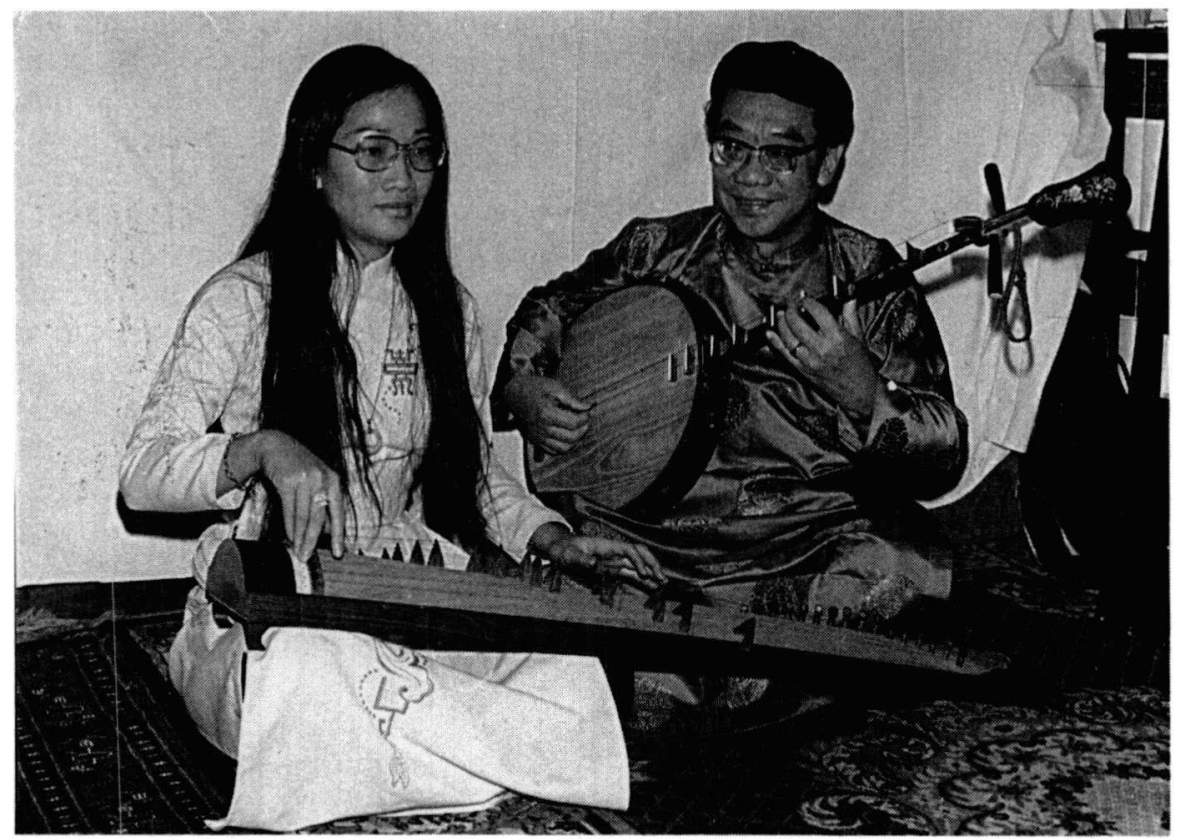

Tràn Van Khê (luth dàn nguyêt) et sa fille Tràn Thi Thuy Ngoc (cithare dàn tranh).

De ce double héritage, mon père a d'abord été tenté par la composante occidentale. Il y voyait la source d'un enrichissement pour la musique vietnamienne. Aussi passait-il la majeure partie de son temps dans sa jeunesse à pratiquer à la guitare une musique hybride en compagnie de son cousin violoniste Nguyên My Ca. A cette époque, il croyait fermement que l'apport de la musique européenne allait permettre de perfectionner et d'internationaliser la musique vietnamienne. Ce n'est que plus tard, lorsqu'il commença à voyager, qu'il devint l'ardent défenseur de la musique traditionneé qu'on connaît aujourd'hui.

De ses quatre enfants, seule ma sœur Tràn Thi Thuy Ngoc, née en 1950, et moi-même, né en 1944, allions nous tourner vers la musique. Ma sœur enseigne actuellement la cithare vietnamienne au Centre d'étude des musiques orientales (CEMO) à Paris et donne fréquemment des concerts avec mon père. Quant à moi, après avoir suivi des études de solfège et de violon au Conservatoire national de musique de Saïgon, c'est à Paris, dès 1961, que j'ai véritablement "découvert" la musique traditionnelle au contact de mon père qui est par la suite devenu mon maître. Tout en suivant ses cours au CEMO et à la Sorbonne, j'ai aussi eu la chance d'être sensibilisé à de nombreuses expressions musicales du monde et d'aborder notamment le zarb iranien avec Djamchid Chemirani, le chant dhrupad avec les frères Dagar, la vînâ avec Nageswara Rao, la vièle chinoise nan $h u$ avec Cheng Shui Cheng, la guimbarde européenne avec John Wright 


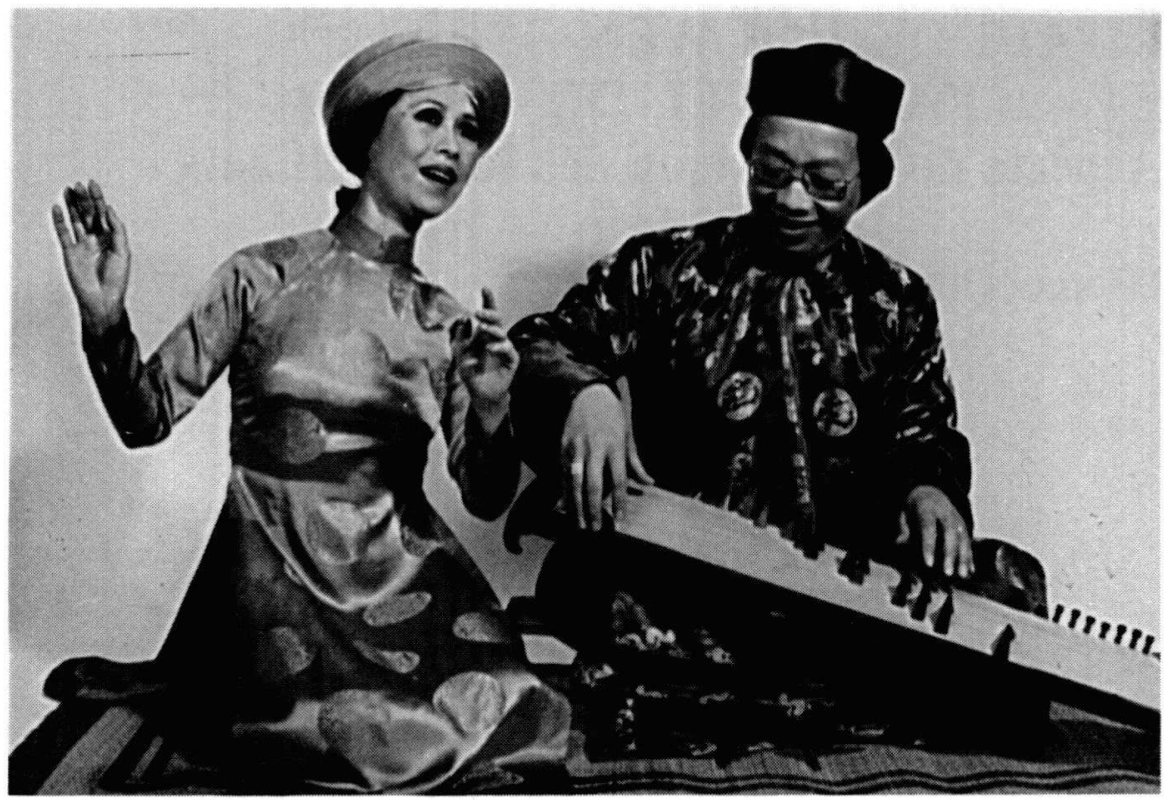

Tràn Quang Hai (cithare dàn tranh) et son épouse la chanteuse Bach Yên.

et la pratique du gamelan javanais avec Mas Putra. Combinées avec certaines expériences en musique contemporaine européenne, ces rencontres m'ont permis de développer une vision large des musiques d'Orient et d'Occident.

Dès 1969, mon père m'a associé à un essai de «renouvellement» de la musique traditionnelle vietnamienne par le développement d'improvisations mélodico-rythmiques inspirées notamment de l'interprétation des râgas dans le nord de l'Inde. Cette tentative a été concrétisée par la publication, en 1976, d'un disque intitulé Nouvelle musique traditionnelle (OCORA 558 512). Soumis à plusieurs musiciens vietnamiens, ces enregistrements ont rencontré l'adhésion autant des jeunes étudiants que des vieux maîtres.

J'aimerais encore ajouter que mon mariage avec Bach Yên, chanteuse de variétés vietnamiennes, a été pour moi la source d'un enrichissement musical nouveau, en particulier dans la manière de présenter nos concerts d'une façon à la fois originale et respectuese de la tradition.

Ainsi, en cinq générations, notre famille témoigne des mutations profondes qu'a subies la musique de notre pays. De l'artiste de cour au musicien transplanté dans un autre milieu culturel, en passant par ceux ayant subi les contrecoups de la guerre et de l'occidentalisation, nous incarnons un peu l'histoire de la musique vietnamienne depuis plus d'un siècle. A ce jour, la sixième génération n'a pas encore donné de bons signes pour la relève; mais je ne perds pas espoir pour autant! 